\title{
1D Nanostructures: Controlled Fabrication and Energy Applications
}

\author{
Jian Wei, ${ }^{1}$ Xuchun Song, ${ }^{2}$ Chunli Yang, ${ }^{1}$ and Michael Z. $\mathrm{Hu}^{3}$ \\ ${ }^{1}$ College of Materials and Mineral Resources, Xi'an University of Architecture and Technology, Xian 710055, China \\ ${ }^{2}$ Department of Chemistry, Fujian Normal University, Fuzhou 350007, China \\ ${ }^{3}$ Energy and Transportation Science Division, Oak Ridge National Laboratory, Oak Ridge, TN 37831, USA
}

Correspondence should be addressed to Jian Wei; weijian@xauat.edu.cn

Received 25 September 2013; Accepted 25 September 2013

Copyright (c) 2013 Jian Wei et al. This is an open access article distributed under the Creative Commons Attribution License, which permits unrestricted use, distribution, and reproduction in any medium, provided the original work is properly cited.

One-dimensional (1D) nanostructures possess fascinating physical properties determined by their special shapes and structures and have wide applications in solar energy conversion, thermoelectric devices, energy storage technology, and so forth. To deal with the rising energy and environmental problems, considerable research has been stimulated on preparation technologies of novel 1D nanostructures and exploring their energy applications. The latest progress, including controlled fabrication methods, characterization, composite structure, and ways to enhance the efficiency of energy conversion, needs to be summarized and ideas exchanged need to be in the entire community to accelerate the development of 1D nanostructures.

A total of 7 articles are presented in this current special issue. The issue focuses on the latest progress in fabrication techniques and properties of energy saving and converting of $1 \mathrm{D}$ nanomaterials. In addition, nanofluid, antireflection coating, polymer solar cell, and nanoparticle are also reported in this issue.

1D nanomaterials are addressed in three manuscripts. S. J. Cho et al. report a novel one-step process to fabricate patternable hierarchical structures consisting of microstructures and one-dimensional nanostructures using a sacrificial layer. Using their method, they fabricated patterned hierarchical structures with the ability to control the shape and density of the nanostructure. H.-B. Cho et al. report the linear assemblies of carbon nanotubes (CNTs) fabricated by applying DC and switching DC electric fields in polysiloxanebased nanocomposite films. The assembly structure enhances the thermal and electrical conductivities and the optical transmittance of the polysiloxane/CNTs nanocomposites. Single-crystalline $\mathrm{TiO}_{2}$ nanorod arrays decorated with CdSe quantum dots were synthesized by Y. Li and his coworkers. A significant improvement of the photovoltaic performance for quantum-dots-sensitized solar cell based on the $\mathrm{CdSe}-\mathrm{TiO}_{2}$ nanostructure was obtained in their work.

Inverted configuration polymer solar cells (IPSCs) were prepared by Y. Xin et al., using $\mathrm{Cs}_{2} \mathrm{CO}_{3}$ modified indium tin oxide substrates as cathode and $\mathrm{MoO}_{3} / \mathrm{Al}$ as anode. The power conversion efficiency of IPSCs was improved to $1 \%$ when the interfacial $\mathrm{Cs}_{2} \mathrm{CO}_{3}$ layers were conducted with 15 minute UV-ozone treatment.

C.-F. Chen et al. used the finite difference time domain method to analyze the antireflection effect of subwavelength structure in a spectral range from $400 \mathrm{~nm}$ to $800 \mathrm{~nm}$. It is found that the antireflection function has obviously decreased in different ratios of the added small conical structures. Such antireflection pattern is useful for solar cells, photodetectors, LEDs, and high-end imaging lens.

Two manuscripts deal with the nanofluid and $\mathrm{Al}_{2} \mathrm{O}_{3}$ nanoparticles, respectively. In one paper, silver nanofluid was prepared by electrical discharge machining system. The relationship of process parameters to the material removal rate of silver electrode and silver ion output rate in the fluid was also quantified. In another one, V. Piriyawong et al. reported the preparation of $\mathrm{Al}_{2} \mathrm{O}_{3}$ nanoparticles by laser ablation of an aluminum target in deionized water.

We are much honored to be invited to compile this special issue and pleased to see the latest progress of fabrication and energy applications of $1 \mathrm{D}$ nanomaterials and their relative 
research fields. We believe that these papers will promote development of $1 \mathrm{D}$ nanomaterials and enrich our understanding of the relative key scientific problems.

\section{Acknowledgments}

The editors thank the authors as well as the reviewers for their constructive contributions and efforts in the prepared process of this special issue.

Jian Wei Xuchun Song Chunli Yang Michael Z. Hu 

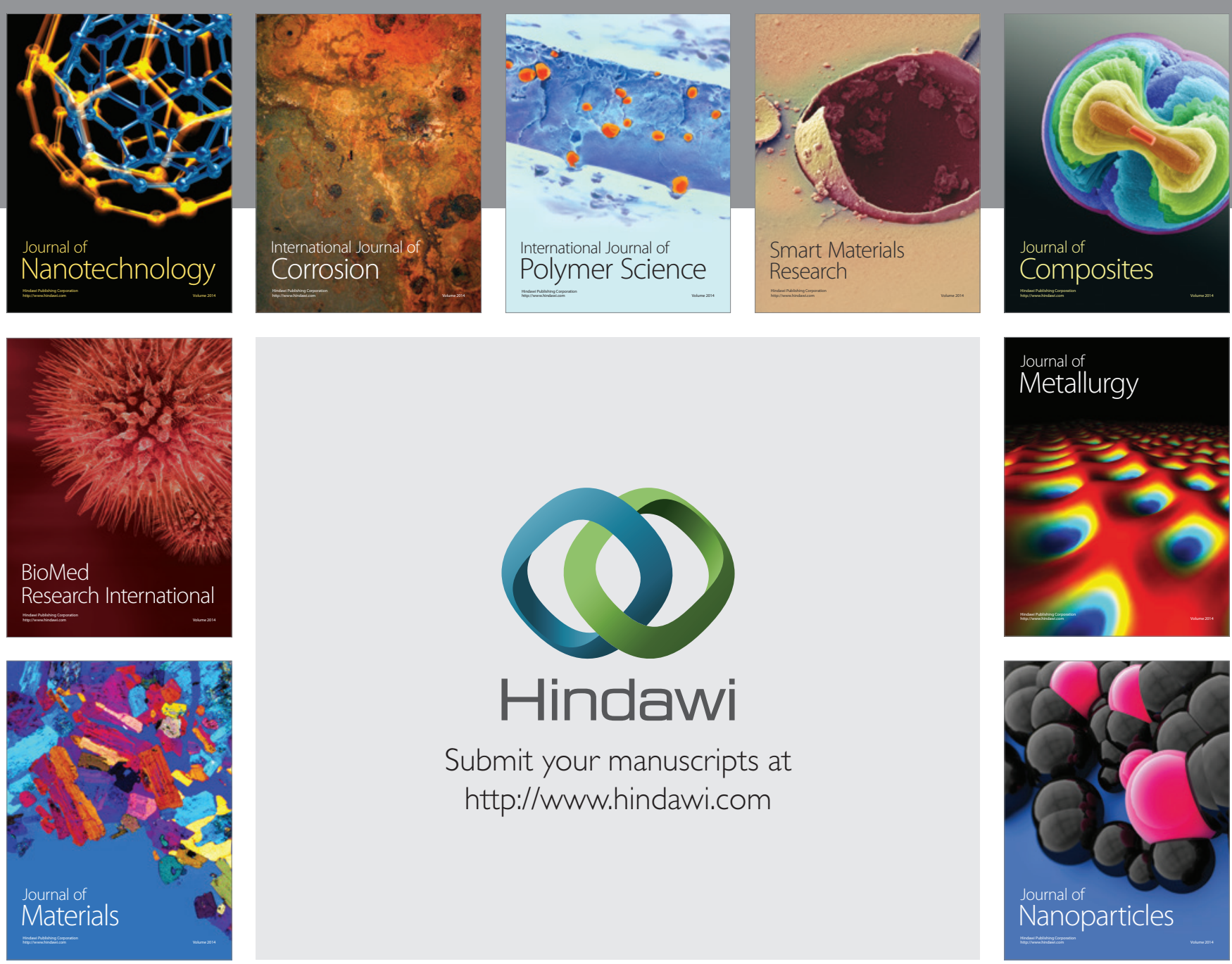

Submit your manuscripts at http://www.hindawi.com
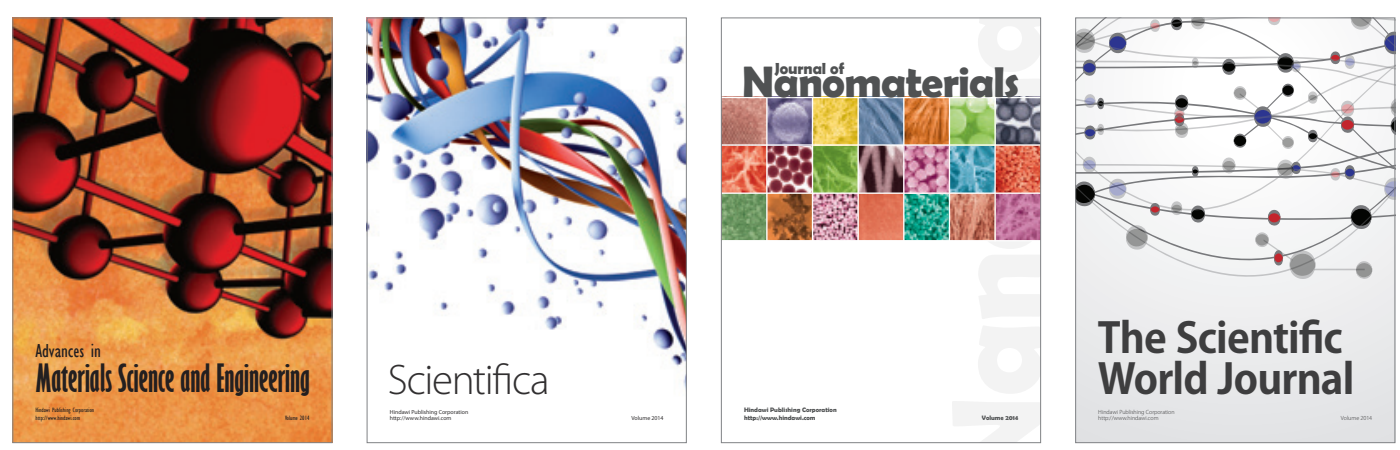

\section{The Scientific World Journal}
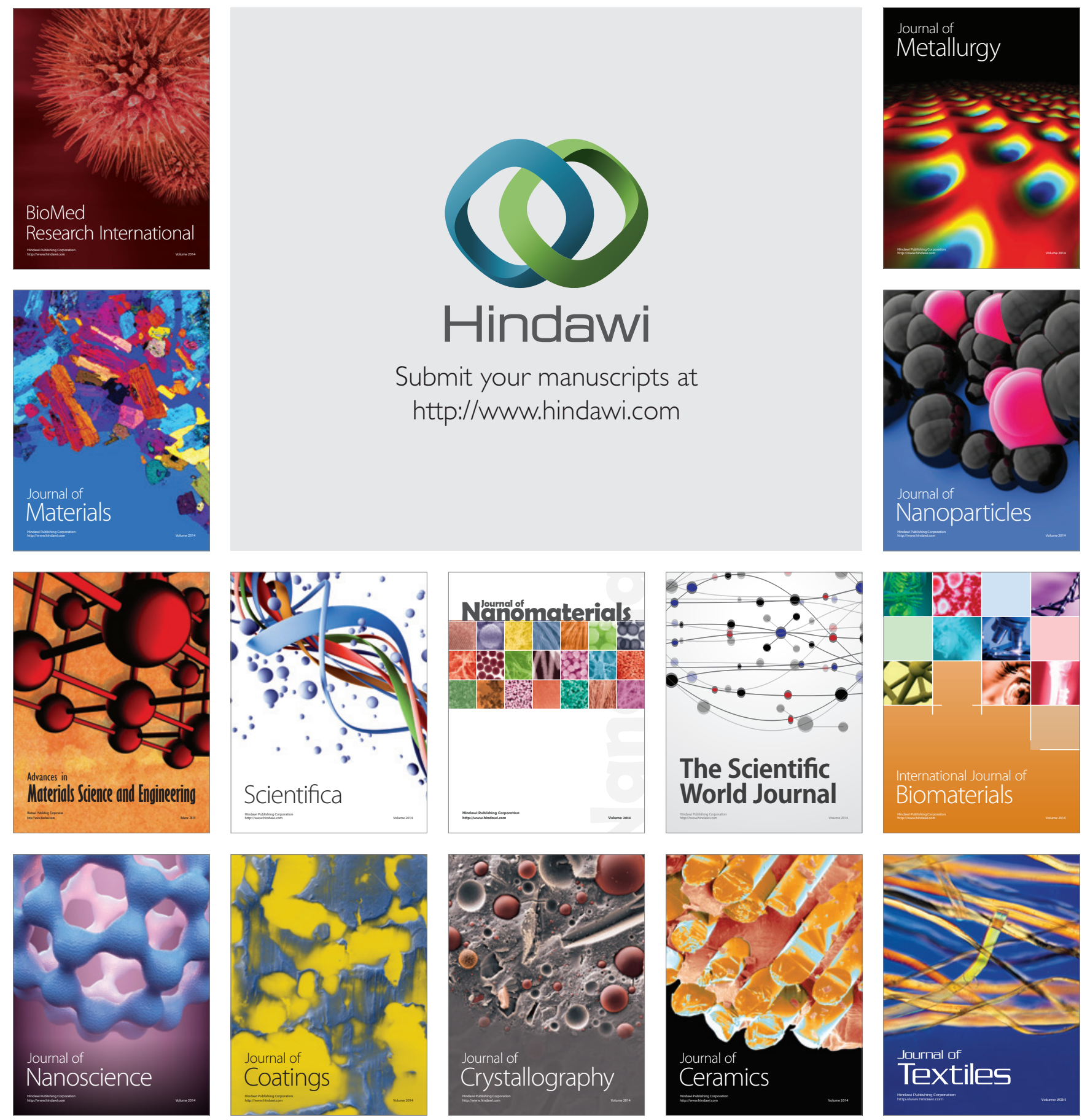